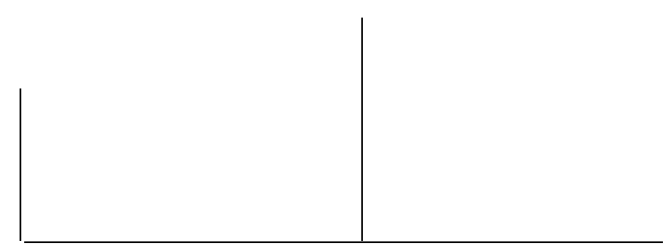

Rev. Latinoam. Psicopat. Fund., X, 3, 554-558

Freedom \& Neurobiology:

Reflections on Free Will, Language, and Political Power

John Searle

Columbia University Press, 113 págs.

Conversations of consciousness: What the Best Minds Think About the Brain, Free Will, and What It Means to be Human

Susan Blackmore

Oxford University Press, 288 págs.

Four Views on Free Will,

John Martin Fischer et al.

Blackwell Publishing, 2007, 272 págs.

Stephen Cave

\title{
Eu penso, portanto sou, eu penso
}

Filósofos vêm debatendo o livre-arbítrio há milênios, mas descobertas recentes mostram que, quando se chega a uma decisão, a mente tem pouca participação.

Se eu pudesse escolher livremente, escolheria ser mais engraçado. Sempre escolheria ter o direito a respostas prontas sagazes para desarmar os adversários e agradar os amigos. Mas infelizmente não é assim. Meu quinhão é composto dos mesmos velhos cacos mancos que vêm atrapalhar, queira eu ou não, como tias inconvenientes em um casamento.

Com certeza, se tivéssemos livre-arbítrio, poderíamos todos escolher ter habilidades para os jogos de palavras, combinadas com a benevolência de Bob Geldof. Mas não podemos. E este é um fato comprovado em laboratório.

* Publicado originalmente em Financial Time, March 24/ March 252007. 


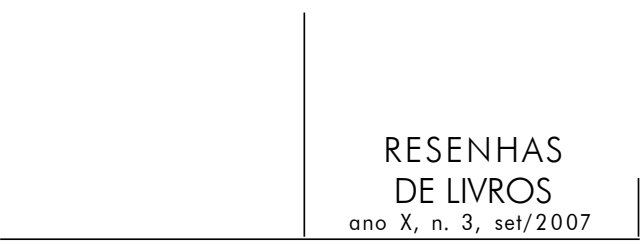

Mas logicamente temos livre-arbítrio, você deve estar pensando. Você pode provar isto, por exemplo, ao escolher levantar seu braço até uma determinada altura nos próximos cinco segundos. Vá em frente. Já levantou? Foi fácil. Por sua própria vontade, na hora em que escolheu, você moveu seu braço: CQD.

Mas o neurocientista americano Benjamin Libet mostrou que antes de qualquer movimento como este, há uma preparação característica da atividade elétrica no cérebro. E esta preparação acontece aproximadamente meio segundo antes da sua "decisão" consciente de mover o braço. Assim, no momento em que você pensa: "OK, vou mover meu braço", seu corpo já percorreu metade do caminho. Isto significa que sua experiência consciente de tomar uma decisão experiência associada ao livre-arbítrio - é só um tipo de acréscimo, uma reflexão posterior que somente acontece uma vez o cérebro já tendo começado seu trabalho. Em outras palavras, seu cérebro está fazendo seu trabalho efetivo, ao fazer suas mãos virarem as páginas desta revista ou alcançarem sua xícara de chá, e durante todo o tempo sua consciência segue um pouco atrás.

É como se, depois de anos dirigindo seu carro, você descobrisse que o volante não está preso a nada e que o carro vai para onde quer.

Dois neurocientistas que trabalham na Austrália fizeram a descoberta de Libet dar um passo adiante. Eles acharam que, quando era pedido para as pessoas movimentarem sua mão esquerda ou direita, era possível influenciar a escolha por estimulação eletrônica de certas partes do cérebro. Assim, por exemplo, os cientistas podiam forçar os sujeitos a sempre escolherem movimentar sua mão esquerda. Mas, apesar de sua escolha ser eletronicamente dirigida, esses pacientes continuavam a afirmar que estavam escolhendo livremente qual mão mover.

Então, não somente seu volante está girando em falso, mas se seu carro estivesse sendo guiado por controle remoto por uma outra pessoa, você nem mesmo iria perceber. Toda vez que virar para a esquerda, você apenas move seu volante de brinquedo e pensa: "Sim, eu queria virar para a esquerda".

Graças à moderna tecnologia de neuroimagem, sabemos agora que nossas mentes - nossa consciência, nossa vida mental - são um produto da atividade no cérebro. $\mathrm{O}$ que o experimento de Libet e outros que vieram depois mostram é que mesmo quando temos a experiência consciente de decisão, nossos cérebros efetivamente já resolveram por nós. O livre-arbítrio é uma ilusão.

Mas, se isto for verdade, as implicações para os nossos sistemas de moral, de crime e castigo, são terríveis. Nós apenas punimos aqueles que achamos que agiram errado voluntariamente - não aqueles que literalmente não tiveram escolha e somente agiram. $\mathrm{O}$ fato de Eva ter comido a maçã estava tão predeterminado quanto as folhas caírem no chão no outono. Nenhum de nós poderia ser em nenhum momento responsabilizado por nossas ações. Por caminhos muito 


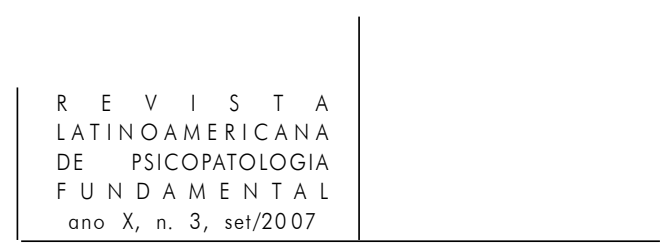

diferentes, três livros tratam da questão de se somos livres e o que significa se não o formos.

A neurocientista Susan Greenfield, uma entre os 21 eminentes pensadores entrevistados por Susan Blackmore em seu Conversation on Consciousness: What the Best Minds Think About the Brain, Free Will and What It Means to be Human (Conversas sobre a consciência: o que as melhores mentes pensam sobre o cérebro, livre-arbítrio e $O$ que significa ser humano), está preocupada. As implicações abrangem "toda a vida", afirma ela, "o quanto uma criança na escola se sente responsável e sente que seu destino está em suas próprias mãos". Uma outra entrevistada, a filósofa Pat Churchland, preocupa-se com "qual será o impacto do desenvolvimento do conhecimento das causas genéticas e neurobiológicas da violência irracional no direito criminal".

O impacto poderia ser revolucionário. Imagine, por exemplo, duas mulheres - Thelma e Louise - que ouvem rumores de que seus maridos estão tendo um caso. Thelma espera que seu marido volte para casa para ouvir a sua versão dos fatos. Louise espera que seu marido volte para casa e atira nele quando ele entra. De fato, nenhum dos maridos estava tendo um caso.

Louise é acusada de tê-lo assassinado friamente. Não há motivo, diz o promotor, para que não tenha agido como Thelma, que, no final das contas, estava exatamente na mesma posição. Não é bem assim, diz o advogado de defesa de Louise, produzindo um mapa de seu cérebro antes de ela ouvir a fofoca. Depois ele mostra ao júri como a notícia fez este neurônio disparar, fazendo outros neurônios dispararem, o que finalmente fez com que o dedo de Louise puxasse o gatilho. Ele afirma que esta cadeia causal contínua a levou inevitavelmente, ao escutar o rumor de que seu marido era infiel, à terrível posição em que agora se encontrava. Thelma teve a sorte de possuir um cérebro como o seu, disse ele. Louise não fora tão afortunada. Certamente, como vítima das imutáveis leis da natureza, esta pobre viúva não mereceria piedade em vez de punição?

Pode ser longo o caminho antes de ser possível mapear o disparo dos neurônios de um indivíduo. Mas já sabemos que, por trás de toda boa ou má ação, por trás de todo santo ou pecador, existe apenas a ativação mecânica de milhares de pequenos neurônios.

Muitos vão achar difícil aceitar isso. Mas nosso crescente conhecimento sobre como funciona o cérebro já está modificando a forma de encararmos o comportamento criminoso. Churchland cita o exemplo de pessoas com baixo nível de MAOA, uma enzima essencial para o trabalho adequado do cérebro. O déficit de MAOA está associado com impulsividade e agressão, e, portanto, altos índices de criminalidade. Aqueles que sofrem tanto de um déficit de MAOA quanto de uma criação abusiva "estão virtualmente determinados a serem irracional e autodestrutivamente violentos", afirma ela. 


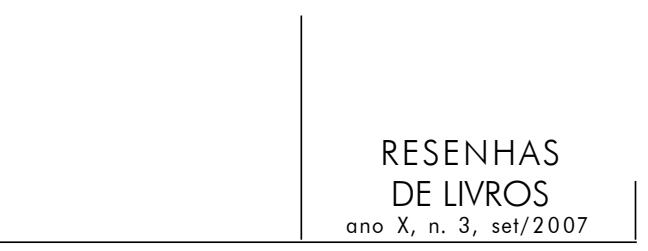

Já está amplamente evidente que a prisão é um lugar para onde efetivamente a sociedade manda aqueles cujo cérebro não funciona adequadamente. Um relatório apresentado no mês passado sugeriu que mais de um quarto dos quase 80.000 prisioneiros do Reino Unido têm QI abaixo de 80 e suspeita de alguma incapacidade de aprendizagem, tais como formas de autismo e dislexia. Um outro estudo feito em um Instituto de Jovens Infratores mostrou que se fossem dados aos prisioneiros minerais e ácidos graxos essenciais ao bom funcionamento do cérebro, eles cometeriam $37 \%$ menos infrações violentas.

Quando sabemos que a estrutura do cérebro de alguém torna-o muito provavelmente uma ameaça para a sociedade, vamos cada vez mais ser confrontados entre a escolha de uma intervenção médica - mesmo que obrigatória - ou saber que poderíamos ter prevenido um crime terrível. "As intervenções podem nem sempre ser boas, mas certamente também não é bom ir para a cadeia”, diz Churchland.

Nada disso será surpresa para os filósofos. Muitos suspeitam há tempos de que os seres humanos estão sujeitos a leis causais como o resto da natureza. Eles apenas não sabem como. Como escreveu em 1676 o filósofo holandês Espinoza, "os homens se iludem se pensam que são livres, uma opinião que consiste simplesmente nisso, em que são conscientes de suas ações e ignorantes das causas pelas quais são determinadas".

Aonde dois mil e quinhentos anos de enfrentamento nos levou pode ser visto em Four Views on Free Will (Quatro visões sobre o livre-arbítrio), o mais recente livro da série "Grandes Debates em Filosofia", da Blackwell, a ser publicado no próximo mês. O leigo pode ficar surpreso ao ouvir que há quatro visões sobre o livre-arbítrio, em vez de simplesmente a visão que você tem sobre isto ou não. Mas a maioria dos filósofos, de Aristóteles a Thomas Hobbes, seguiu pelo caminho do meio, afirmando que a verdade do determinismo é de alguma forma compatível com o grau de liberdade e responsabilidade em relação a nossas ações.

Com efeito, nenhum dos quatro filósofos neste volume sugere que devemos abrir mão completamente do jogo da culpa. Por exemplo, Derk Pereboom reconhece que nossa falta de livre-arbítrio significa que devemos repensar a moral - mas não vê isso como uma coisa ruim. Isto nos levaria, sugere ele, a reformas sensíveis, tais como desviar o foco do sistema de justiça criminal do castigo retribuidor para a reeducação e dissuasão - ou para a proteção da sociedade: "Suponha que um assassino em série continue a representar um grande perigo para a comunidade. Mesmo que não seja moralmente responsável por seus crimes, seria tão legítimo detê-lo quanto colocar em quarentena a carreira de uma doença mortal transmissível".

Mas o que este livro mais evidencia é que, enquanto os cientistas fazem verdadeiros progressos no estudo do cérebro em laboratórios por todo o mundo, 


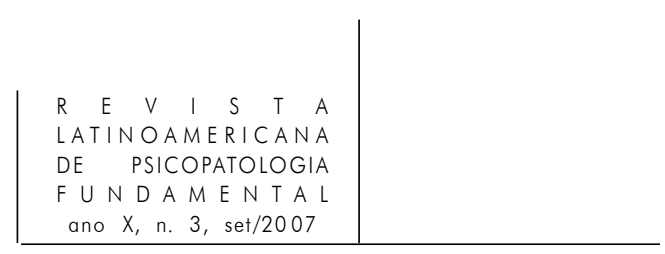

muitos filósofos seguem encarando estrábicos seus umbigos. Agora, mais do que nunca, precisamos que nossos filósofos nos ajudem a dar sentido ao que a ciência nos apresenta. Mas a maior parte deste livro é dedicada a uma briga interna girando em torno de alguns experimentos considerados bastante implausíveis, todos conduzidos em um jargão misterioso, desconsiderando o desenvolvimento exterior à academia.

Mas tal crítica não pode ser dirigida a John Searle. Hoje um dos mais importantes filósofos americanos, Searle procurou ao longo de sua carreira reunir os achados da ciência contemporânea e os problemas filosóficos antigos. Em sua recente pequena obra, Freedom and neurobiology (Liberdade e neurobiologia), ele coloca a questão do livre-arbítrio no contexto do que ele considera a grande questão: como nós, humanos, concebendo-nos livres, racionais, agentes morais, cabemos em um universo de "partículas físicas insensatas, insignificantes, grosseiras"?

Ele fica intrigado por que, se não temos livre-arbítrio, temos esta experiência singular de tomada de decisão. Se, como a neurociência normalmente sugere, isto é pura ilusão, então "a evolução sempre nos enganou". Mas isto "vai contra tudo o que conhecemos sobre a evolução. Os processos de racionalidade consciente são uma parte tão importante de nossas vidas e, sobretudo, uma parte tão custosa de nossas vidas" que parece impossível não terem "nenhum papel funcional na vida e sobrevivência do organismo".

A alternativa é que de alguma forma a tomada de decisão consciente desempenha um papel - ao menos por vezes - na formatação de nosso comportamento. Talvez nas situações mais complexas, em que ruminamos as alternativas que temos. Searle acredita que um dia seremos capazes de estabelecer isto em laboratório. Assim, de alguma forma, pode ainda parecer que vivemos, nas palavras de Jorge Luis Borges, num "jardim dos caminhos que se bifurcam".

Talvez seja cedo demais para abrir as grades das prisões, fechar as cortes e nos conformarmos às leis implacáveis da natureza. Mas sem sombra de dúvida conforme conhecermos mais sobre os mecanismos da mente, vamos precisar repensar algumas de nossas crenças mais profundas sobre nós mesmos e sobre nossa sociedade. Cada um destes três volumes lança alguma luz sobre o trabalho que precisa ser feito. Mas o livro que realmente faz justiça a esta questão ainda está por ser escrito. 